\title{
Are there too many screw holes in plates for fracture fixation?
}

Hongzhi Lv ${ }^{1 \dagger}$, Wenli Chang ${ }^{2 \dagger}$, Peizhi Yuwen ${ }^{1}$, Na Yang ${ }^{1}$, Xiaoli Yan ${ }^{1}$ and Yingze Zhang ${ }^{1,2^{*}}$

\begin{abstract}
Background: Implant breakage after the fixation of traumatic fractures is rare; however, when it occurs, it is debilitating for the patients and a challenge for surgeons. The purpose of this study was to analyze and identify the independent risk factors for implant breakage of traumatic fractures treated with plate osteosynthesis.

Methods: We reviewed the medical records of patients with a fracture to any part of their four extremities, clavicle, hand or foot, who underwent surgical plate osteosynthesis from January 2005 to January 2015, and who sustained a subsequent implant breakage. Kaplan-Meier univariate and multivariate Cox regressions were performed to identify independent associations of potential risk factors for implant breakage in this cohort.

Results: We identified 168 patients who underwent plate osteosynthesis surgery and had subsequent internal fixator breakage. The mean patient age was $40.63 \pm 16.71$ years (range, 3 to 78 years), with $72.0 \%$ (121) males and 28.0\% (47) females. The average time between surgery and implant breakage was $12.85 \pm 12.42$ months (range, 1 to 60 months). In the final regression model, we show that inserting screws close to the fracture line is an independent predictive risk factor for implant breakage (HR, 2.165, 95\%Cl, 1.227 to $3.822 ; P=0.008)$.

Conclusions: We found that inserting screws close to the fracture line is related to an increased risk of internal fixator breakage in patients treated with plate osteosynthesis after fracture. Plates with additional holes likely lead to an increased risk of implant breakage, presumably because surgeons cannot resist inserting extra screws into the holes adjacent to the fracture line, which reduces the stiffness of the plate. We have addressed this problem by designing a plate without holes adjacent to the fracture line.
\end{abstract}

Keywords: Traumatic fracture, Plate osteosynthesis, Risk factors, Implant breakage, Internal fixation

\section{Background}

Internal fixator breakage occurs in approximately $3.5 \%$ to $13.3 \%$ of patients during internal fixation surgery followup $[1,2]$. These complications are a challenge for even the most experienced surgeons, and can cause the patient substantial functional impairments, such as persistent and prolonged physical and psychological disabilities.

Previous studies show that risk factors for implant breakage include age, American Society of Anesthesiologists (ASA) score, fall from a height, body mass index, systemic patient comorbidities, patient postoperative

\footnotetext{
*Correspondence: zhangyingzelv@126.com

${ }^{\dagger}$ Equal contributors

${ }^{1}$ Editorial department, The Third Hospital of Hebei Medical University, NO.139

Ziqiang Road, Shijiazhuang 050051, People's Republic of China

${ }^{2}$ Department of Orthopedic Surgery, The Third Hospital of Hebei Medical

University, NO.139 Ziqiang Road, Shijiazhuang 050051, People's Republic of China
}

(c) The Author(s). 2017 Open Access This article is distributed under the terms of the Creative Commons Attribution 4.0 International License (http://creativecommons.org/licenses/by/4.0/), which permits unrestricted use, distribution, and reproduction in any medium, provided you give appropriate credit to the original author(s) and the source, provide a link to the Creative Commons license, and indicate if changes were made. The Creative Commons Public Domain Dedication waiver (http://creativecommons.org/publicdomain/zero/1.0/) applies to the data made available in this article, unless otherwise stated. noncompliance, local pathology at the fracture site, surgeons who treat a high number of patients, and surgeon technical error; this includes the use of specially designed plates rather than plates routinely used by other surgeons for treatment [3-6]. Several fixation characteristics linked with construct strength and resilience have been biomechanically evaluated and found to be related to the risk of failure, including the number of screws, the density of screws (number of screws/the number of plate holes), and the working length (plate length spanning the fracture site between two screws on each side adjacent to the fracture) [7-10]. However, there is limited data available in the literature to validate these concepts from a clinical perspective.

This study aims to investigate a large population of patients who experienced implant breakage after plate of a traumatic fracture(s) to determine the risk factors associated with this specific complication. 


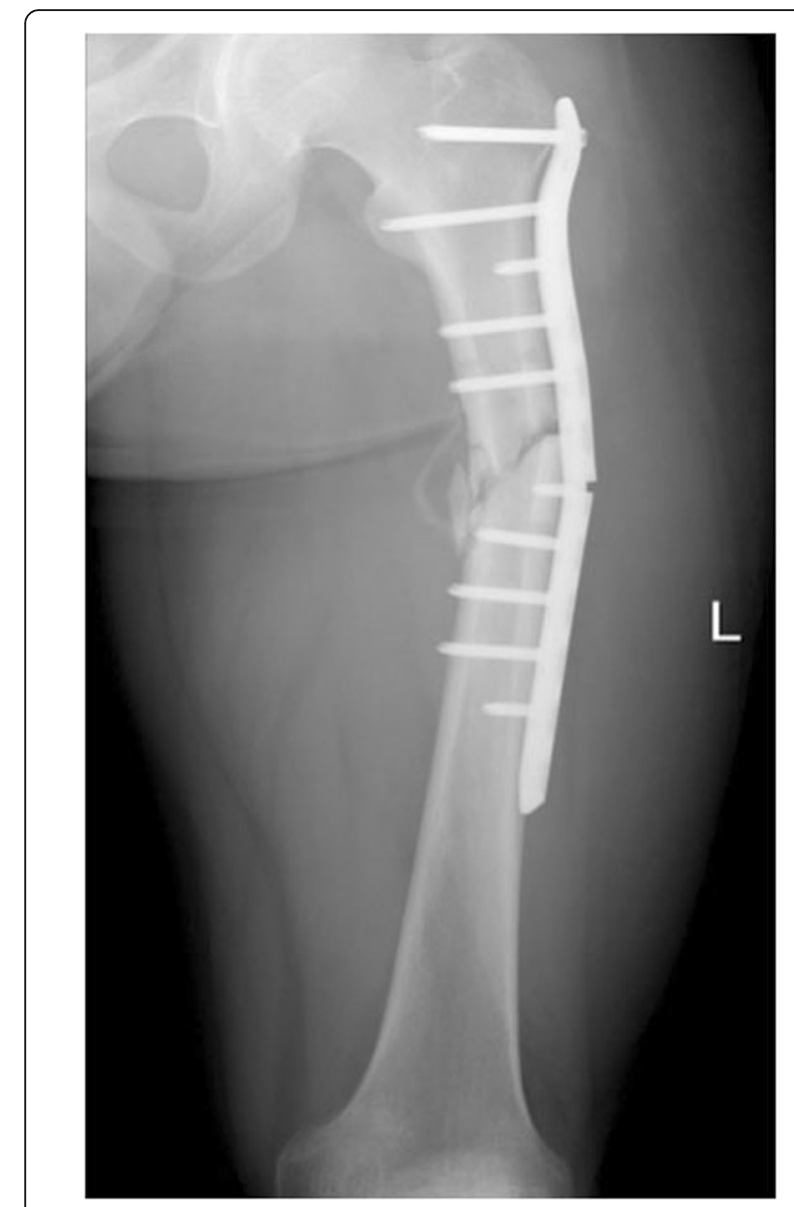

Fig. 1 The anteroposterior radiograph of proximal femur shows the plate breakage and nonunited proximal femoral shaft fracture

\section{Methods}

\section{Data sources}

We retrieved and reviewed the medical records of patients who were admitted to the Third Hospital of Hebei Medical University in China from January 2005 to January 2015. We included in the study patients who had any fracture to the four extremities, clavicle, hand or foot, who underwent treatment via closed reduction or open reduction and plate osteosynthesis, and who subsequently developed an implant breakage. We excluded patients who sustained direct trauma from the internally fixed fracture, those who experienced a pathological fracture, those with a psychiatric disorder, and those who suffered traumatic brain injury.

We recorded specific characteristics related to the: (1) patient (age, sex, residence, body mass index (BMI), osteoporosis, ASA classification, and medical comorbidities); (2) fracture (side of fractured limb, mechanism of injury, fractured site, fractured bones, fracture pattern, AO/OTA classification, seasonality, open/closed fracture, number of fractures); (3) surgery (shape and type of the used plate, number of used plates, ancillary fixation, number of ancillary K-wires, number of ancillary screws, inserting screws closely adjacent to the fracture line, number of empty screw holes adjacent to the fracture line, number of plate holes, number of plate screws, name and level of the surgeon performing the operation, open or closed reduction of the fracture, postoperative complication), and (4) implant breakage (breakage site within/outside the fracture line, screw slack off the hole, type of broken plate, and most possible underlying cause for the breakage).

\section{Breakage time}

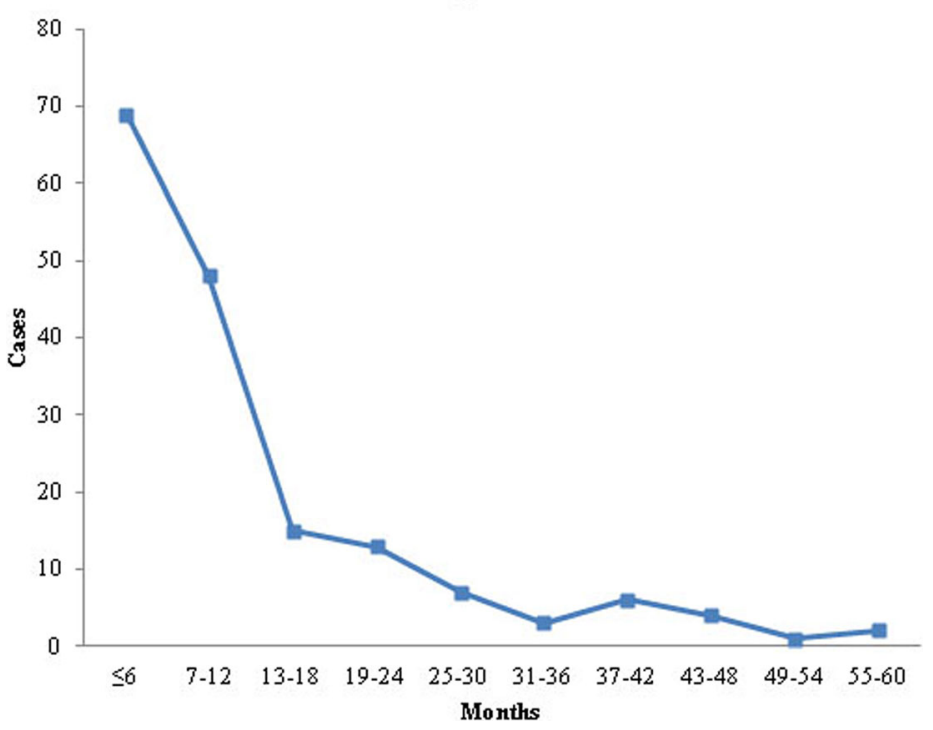

Fig. 2 The interval between plate osteosynthesis surgery and implant breakage and the corresponding number of cases with implant breakage during the study period 
Table 1 Characteristics of Patients with Internal fixation breakage

\begin{tabular}{|c|c|c|c|c|}
\hline Issues & $\begin{array}{l}\text { Interval between internal fixation and } \\
\text { implant breakage, months }(\mathrm{M}(\mathrm{QR}))\end{array}$ & $n(\%)$ & $x^{2}$ value & $P$ value \\
\hline \multicolumn{5}{|l|}{ Patients characteristics } \\
\hline Age (years) & & & 5.212 & 0.634 \\
\hline $0-10$ & 6.0 & $3(1.8)$ & & \\
\hline $11-20$ & $6.0(9.0)$ & $9(5.4)$ & & \\
\hline $21-30$ & $8.0(11.2)$ & $32(19.0)$ & & \\
\hline $31-40$ & $9.0(21.3)$ & $44(26.2)$ & & \\
\hline $41-50$ & 10.0(8.0) & 29(17.3) & & \\
\hline $51-60$ & $10.5(16.2)$ & $22(13.1)$ & & \\
\hline $60-69$ & $9.0(14.0)$ & 23(13.7) & & \\
\hline $70+$ & $8.5(21.2)$ & $6(3.6)$ & & \\
\hline Gender & & & 0.008 & 0.927 \\
\hline Male & $9.0(12.5)$ & $121(72.0)$ & & \\
\hline Female & $9.0(14.0)$ & $47(28.0)$ & & \\
\hline Body Mass Index (BMI kg/(cm²) & & & 5.398 & 0.249 \\
\hline$<18.5$ & 10.0 & $1(0.6)$ & & \\
\hline $18.5-23.9$ & $6.5(11.0)$ & $56(33.3)$ & & \\
\hline $24.0-27.9$ & $9.0(8.5)$ & $56(33.3)$ & & \\
\hline $28-30$ & $10.0(17.0)$ & $39(23.2)$ & & \\
\hline$\geq 30$ & 10.8(8.3) & $16(9.5)$ & & \\
\hline Residence & & & 2.043 & 0.153 \\
\hline Urban & $7.0(9.0)$ & $36(21.4)$ & & \\
\hline Rural & $9.0(12.8)$ & 132(78.6) & & \\
\hline Osteoporosis & & & 0.746 & 0.388 \\
\hline None & $9.0(12.0)$ & 149(88.7) & & \\
\hline Yes & $9.0(16.0)$ & 19(11.3) & & \\
\hline ASA classification & & & 2.444 & 0.486 \\
\hline 1 & $8.0(8.0)$ & $17(10.1)$ & & \\
\hline 2 & $9.0(13.5)$ & 133(79.2) & & \\
\hline 3 & $8.0(17.0)$ & 15(8.9) & & \\
\hline 4 & $10.0(4.0)$ & $3(1.8)$ & & \\
\hline Medical comorbidities & & & 6.829 & 0.145 \\
\hline None & $9.0(13.0)$ & $141(83.9)$ & & \\
\hline Diabetes & $6.0(6.0)$ & $9(5.4)$ & & \\
\hline Hypertension & 11.0(11.0) & $10(6.0)$ & & \\
\hline Cardiovascular system disease & $4.0(7.0)$ & $7(4.2)$ & & \\
\hline Others* & 5.0 & $1(0.6)$ & & \\
\hline \multicolumn{5}{|l|}{ Fracture characteristics } \\
\hline Fracture pattern & & & 3.012 & 0.390 \\
\hline Comminuted fracture(s) & $9.3(14.0)$ & $70(41.7)$ & & \\
\hline Wedge fracture(s) & $6.0(8.5)$ & $78(46.4)$ & & \\
\hline Oblique fracture(s) & 14.0(23.0) & $13(7.7)$ & & \\
\hline Transverse fracture(s) & $10.0(26.0)$ & $7(4.2)$ & & \\
\hline
\end{tabular}


Table 1 Characteristics of Patients with Internal fixation breakage (Continued)

\begin{tabular}{|c|c|c|c|c|}
\hline AO/OTA classification & & & 0.103 & 0.950 \\
\hline Type A & $9.0(13.5)$ & $46(27.4)$ & & \\
\hline Type B & $9.0(10.0)$ & $88(52.4)$ & & \\
\hline Type C & $8.5(14.3)$ & $34(20.2)$ & & \\
\hline Fractured bones & & & 3.288 & 0.511 \\
\hline Humerus & $9.5(18.7)$ & $16(9.5)$ & & \\
\hline Radius/ulna & 10.0(8.0) & $15(8.9)$ & & \\
\hline Femur & $9.0(14.0)$ & $87(51.8)$ & & \\
\hline Tibia/fibula & $9.0(11.0)$ & $37(22.0)$ & & \\
\hline Others (Hand, foot and clavicle) & $6.0(10.0)$ & $13(7.7)$ & & \\
\hline Weight/not weight limbs & & & 14.466 & $<0.001^{*}$ \\
\hline Lower limb (Weight bearing bones) & $7.0(7.0)$ & 133(79.2) & & \\
\hline Upper limb (Non-weighted bearing bones) & 18.0(18.0) & $35(20.8)$ & & \\
\hline The side of fracture limbs & & & 0.182 & 0.670 \\
\hline Left & $9.0(13.0)$ & $92(54.8)$ & & \\
\hline Right & $9.5(13.0)$ & $76(45.2)$ & & \\
\hline Seasonality & & & 1.490 & 0.685 \\
\hline Spring & 10.5(19.0) & $46(27.4)$ & & \\
\hline Summer & $9.5(9.0)$ & $40(23.8)$ & & \\
\hline Autumn & $7.0(9.7)$ & $37(22.0)$ & & \\
\hline Winter & $9.0(14.0)$ & $45(26.8)$ & & \\
\hline Open/closed fracture & & & 0.016 & 0.899 \\
\hline Open fracture & $8.5(13.2)$ & $26(15.5)$ & & \\
\hline Closed fracture & $9.0(13.3)$ & $142(84.5)$ & & \\
\hline Mechanism of injury & & & 3.600 & 0.463 \\
\hline Motor vehicle accident & $9.0(13.0)$ & $99(58.9)$ & & \\
\hline Pedestrian fall & $8.5(10.9)$ & $44(26.2)$ & & \\
\hline Crush & $11.5(21.8)$ & $8(4.8)$ & & \\
\hline Fall from height & 11.0(10.1) & $14(8.3)$ & & \\
\hline Sport accident & $6.0(7.0)$ & $3(1.8)$ & & \\
\hline Number of fracture(s) & & & 2.031 & 0.362 \\
\hline 1 & $9.0(12.5)$ & 145(86.3) & & \\
\hline 2 & $6.0(14.5)$ & $14(8.3)$ & & \\
\hline$>2$ & $6.0(10.5)$ & $9(5.4)$ & & \\
\hline \multicolumn{5}{|l|}{ Operation related issues } \\
\hline Number of used plates & & & 1.560 & 0.212 \\
\hline 1 & $12.6(13.0)$ & 159(94.6) & & \\
\hline 2 & $17.4(25.0)$ & $9(5.4)$ & & \\
\hline The shape of used plates & & & 0.961 & 0.916 \\
\hline Straight & $9.0(13.3)$ & 150(89.3) & & \\
\hline L-shape & $9.0(7.7)$ & $8(4.8)$ & & \\
\hline T-shape & $6.0(17.0)$ & $7(4.2)$ & & \\
\hline Y-shape & 24.0 & $1(0.6)$ & & \\
\hline O-shape & 11.0 & $2(1.2)$ & & \\
\hline
\end{tabular}


Table 1 Characteristics of Patients with Internal fixation breakage (Continued)

\begin{tabular}{|c|c|c|c|c|}
\hline \multicolumn{2}{|l|}{ Ancillary fixation } & & \multirow[t]{5}{*}{0.427} & \multirow[t]{5}{*}{0.935} \\
\hline None & $9.0(10.0)$ & 106(63.1) & & \\
\hline K-wire(s) & $11.0(14.0)$ & 19(11.3) & & \\
\hline Screw(s) & $9.0(14.0)$ & $42(25.0)$ & & \\
\hline K-wire(s) and Screw(s) & 8.0 & $1(0.6)$ & & \\
\hline \multicolumn{2}{|l|}{ Number of ancillary K-wire(s) } & & \multirow[t]{4}{*}{0.071} & \multirow[t]{4}{*}{0.965} \\
\hline 0 & $9.0(13.0)$ & 149(88.7) & & \\
\hline 1 & $8.5(11.5)$ & $8(4.8)$ & & \\
\hline$>1$ & 11.0(14.0) & $11(6.5)$ & & \\
\hline \multicolumn{2}{|l|}{ Number of ancillary screw(s) } & & \multirow[t]{5}{*}{7.751} & \multirow[t]{5}{*}{0.054} \\
\hline 0 & $9.0(10.0)$ & 126(75.0) & & \\
\hline 1 & $8.0(6.8)$ & 20(11.9) & & \\
\hline 2 & $9.0(24.0)$ & $11(6.5)$ & & \\
\hline$>2$ & 19.0(21.0) & $11(6.5)$ & & \\
\hline \multicolumn{2}{|c|}{ Inserting screws closely adjacent to the fracture line } & & \multirow[t]{3}{*}{5.674} & \multirow[t]{3}{*}{$0.017^{*}$} \\
\hline None & $9.0(13.0)$ & 146(86.9) & & \\
\hline Yes & $5.5(8.3)$ & $22(13.1)$ & & \\
\hline \multicolumn{2}{|c|}{ Number of empty screw holes adjacent to the fracture line } & & \multirow[t]{6}{*}{6.245} & \multirow[t]{6}{*}{0.182} \\
\hline 0 & $5.5(8.3)$ & $22(13.1)$ & & \\
\hline 1 & $10.0(13.0)$ & $76(45.2)$ & & \\
\hline 2 & $8.5(16.3)$ & $40(23.8)$ & & \\
\hline 3 & $9.0(8.8)$ & $22(13.1)$ & & \\
\hline$>4$ & $9.0(19.5)$ & $8(4.8)$ & & \\
\hline \multicolumn{2}{|l|}{ The type of used plate } & & \multirow[t]{3}{*}{0.122} & \multirow[t]{3}{*}{0.727} \\
\hline Plate(s) & $9.5(10.5)$ & $71(42.3)$ & & \\
\hline Locked plate(s) & $9.0(13.0)$ & $97(57.7)$ & & \\
\hline \multicolumn{2}{|l|}{ Surgeon performing the operation } & & \multirow[t]{3}{*}{0.003} & \multirow[t]{3}{*}{0.953} \\
\hline Chief physician & $9.0(12.5)$ & 129(76.8) & & \\
\hline Associate chief physician & $9.0(14.0)$ & $39(23.2)$ & & \\
\hline \multicolumn{2}{|l|}{ Open or closed reduction of the fracture } & & \multirow[t]{3}{*}{0.460} & \multirow[t]{3}{*}{0.498} \\
\hline Open reduction and internal fixation & $9.0(12.8)$ & 164(97.6) & & \\
\hline Closed reduction and internal fixation & $21.0(17.3)$ & $4(2.4)$ & & \\
\hline \multicolumn{2}{|l|}{ Postoperative complication(s) } & & 6.170 & 0.187 \\
\hline None & $8.0(16.0)$ & $35(20.8)$ & & \\
\hline Fracture nonunion & $9.0(11.8)$ & $112(66.7)$ & & \\
\hline Fracture delayed union & $6.0(35.0)$ & $6(3.6)$ & & \\
\hline Infection & $9.0(14.5)$ & $9(5.4)$ & & \\
\hline Others & $30.0(42.8)$ & $6(3.6)$ & & \\
\hline Postsurgical infection(s) & & & 0.313 & 0.855 \\
\hline None & $9.0(12.5)$ & 154(91.7) & & \\
\hline Superficial infection & $9.0(18.3)$ & $8(4.8)$ & & \\
\hline Deep infection & $7.5(18.2)$ & $6(3.6)$ & & \\
\hline Number of plate holes & & & 17.119 & $<0.001^{*}$ \\
\hline$<5$ & $25.5(24.5)$ & $22(13.1)$ & & \\
\hline
\end{tabular}


Table 1 Characteristics of Patients with Internal fixation breakage (Continued)

\begin{tabular}{|c|c|c|c|c|}
\hline $5-10$ & $8.0(8.3)$ & $69(41.1)$ & & \\
\hline $11-15$ & $9.0(12.0)$ & $60(35.7)$ & & \\
\hline$>15$ & $6.0(5.5)$ & $17(10.1)$ & & \\
\hline Number of inserted screws & & & 6.604 & $0.037^{*}$ \\
\hline$<5$ & $12.0(25.0)$ & $40(23.8)$ & & \\
\hline $5-10$ & $9.0(9.0)$ & 104(61.9) & & \\
\hline 10 & $7.0(7.5)$ & $24(14.3)$ & & \\
\hline \multicolumn{5}{|l|}{ Breakage characteristics } \\
\hline Breakage site within/outside the fracture line & & & 5.196 & $0.023^{*}$ \\
\hline Within & $8.0(10.0)$ & 132(78.6) & & \\
\hline Outside & 11.0(17.3) & $36(21.4)$ & & \\
\hline Screw slack off the hole & & & 0.068 & 0.794 \\
\hline None & $9.0(13.0)$ & 125(74.4) & & \\
\hline Yes & $9.0(13.0)$ & $43(25.6)$ & & \\
\hline Type of broken plate & & & 17.456 & $<0.001^{*}$ \\
\hline Plate(s) & $6.5(8.1)$ & 114(67.9) & & \\
\hline Screw(s) & $12.0(19.5)$ & $54(32.1)$ & & \\
\hline Most possible underlying cause of breakage & & & 6.384 & 0.172 \\
\hline Internal fixator improper selection & $10.0(21.8)$ & $36(21.4)$ & & \\
\hline Premature postoperative training & 10.0(15.0) & $39(23.2)$ & & \\
\hline Too short of a plate utilized & 7.0(8.6) & $34(20.2)$ & & \\
\hline Screw(s) in inappropriate location & $5.0(11.0)$ & $39(23.2)$ & & \\
\hline Others & $8.0(8.3)$ & 20(11.9) & & \\
\hline
\end{tabular}

*Significant at $a=0.05$

All radiographs were reviewed by professors working in the Department of Orthopedic Surgery. If there were any disagreements in assessing the data, a final decision was made by discussion and consensus (Fig. 1).

\section{Statistical analysis}

Statistical analyses were performed with SPSS21.0 (IBM, USA) software. A $P$ value $<0.05$ was considered significant. Cox proportional-hazard regression models were used to perform survival analyses, to identify the risk factors for plate breakage, and to calculate hazard ratios $\left(\mathrm{HR}_{\mathrm{S}}\right)$. A univariate analysis was performed using KaplanMeier curves. Kaplan-Meier curves also provided a graphical comparison of survivorship for the procedures that were used over the period of the study, with the time of implant breakage as the end-point.

\section{Results}

Of the 201 patients identified who underwent surgery from January 2005 to January 2015, 168 patients met the inclusion criteria for the study. The mean age of the population was $40.63 \pm 16.71$ years (range, 3 to 78 years). Among these patients, $72 \%$ (121) were male and 28\% (47) were female. The average time between internal fixation surgery and implant breakage was $12.85 \pm 12.42$ months (range, 1 to 60 months). Implant breakage occurred in 117 patients within less than 1 year, and this accounts for $70 \%$ of all cases (Fig. 2).

The risk factors that were investigated are listed in Table 1. According to the Kaplan-Meier univariate analysis, implant breakage was associated with the weight or not weight limbs $\left(\chi^{2}=14.466, P<0.001\right)$, the type of broken plate $\left(\chi^{2}=17.456, P<0.001\right)$, breakage site within/outside the fracture line $\left(\chi^{2}=5.196, P\right.$ cps 0.023$)$, the number of plate holes $\left(\chi^{2}=17.119, P<0.001\right)$, the number of plate screws $\left(\chi^{2}=6.604, P=0.037\right)$, and inserting screws closely adjacent to the fracture line $\left(\chi^{2}=5.674, P=0.017\right.$, Fig. 3$)$.

Table 2 shows the results from the multivariate Cox regression analysis, which was used to assess the association of risk factors after adjusting for all other potential risk factors. In the final model, "inserting screws adjacent to the fracture line" was identified to be independently predictive of having implant breakage (HR, 2.165; 95\% CI, 1.227 to $3.822 ; P=0.008)$, with a 2.165 -times increased risk of causing internal fixator breakage (Fig. 4). In the study, $13.1 \%$ of surgeons did not adhere to the principle for screw placement, and inserted screws closely adjacent to the fracture line. 


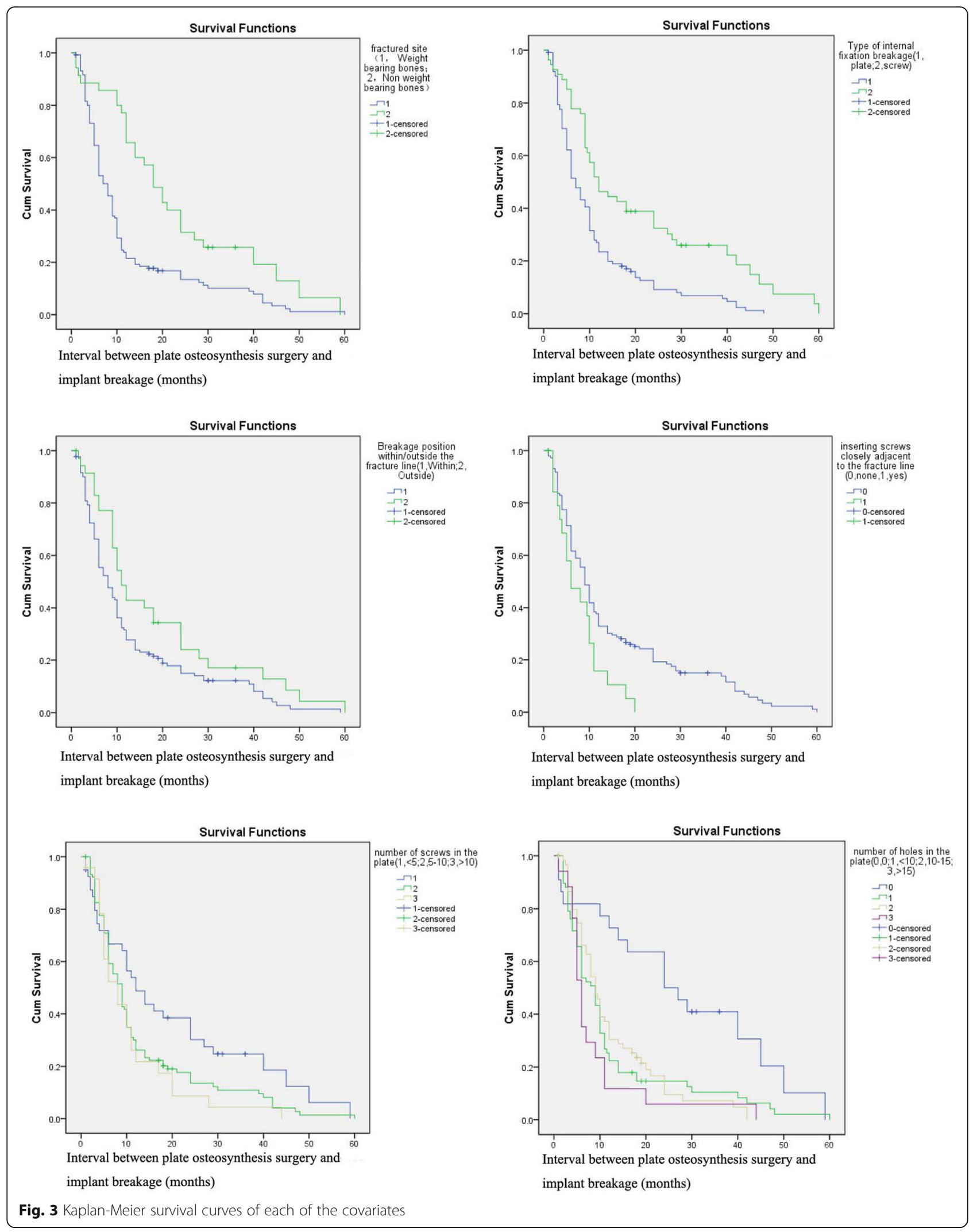


Table 2 Potential Predictors of Internal fixation breakage

\begin{tabular}{|c|c|c|c|c|c|c|c|c|}
\hline Predictor & B & SE & Wald & $P$ value & $H R$ & $95 \% \mathrm{Cl}$ & & \\
\hline Weight/not weight limbs & -0.533 & 0.315 & 2.859 & 0.091 & 0.587 & 0.316 & to & 1.089 \\
\hline Type of broken plate & -0.352 & 0.290 & 1.474 & 0.225 & 0.703 & 0.399 & to & 1.241 \\
\hline Breakage site within/outside the fracture line & -0.143 & 0.278 & 0.266 & 0.606 & 0.866 & 0.502 & to & 1.494 \\
\hline Inserting screws closely adjacent to the fracture line & 0.772 & 0.290 & 7.100 & $0.008^{*}$ & 2.165 & 1.227 & to & 3.822 \\
\hline Number of plate hole(s) & & & 2.855 & 0.414 & & & & \\
\hline$<5$ & -0.993 & 0.649 & 2.343 & 0.126 & 0.370 & 0.104 & to & 1.321 \\
\hline $5-10$ & -0.459 & 0.379 & 1.468 & 0.226 & 0.632 & 0.301 & to & 1.328 \\
\hline $11-15$ & -0.442 & 0.331 & 1.781 & 0.182 & 0.643 & 0.336 & to & 1.230 \\
\hline Number of plate screw(s) & & & 2.633 & 0.268 & & & & \\
\hline$<5$ & 0.651 & 0.447 & 2.128 & 0.145 & 1.918 & 0.799 & to & 4.604 \\
\hline $5-10$ & 0.194 & 0.317 & 0.374 & 0.541 & 1.214 & 0.652 & to & 2.260 \\
\hline
\end{tabular}

${ }^{*} P<0.05$ through multivariate Cox regression analysis

\section{Discussion}

Plate osteosynthesis of a fracture is a common procedure with well-established efficacy for achieving union, reducing pain, and improving function in appropriately selected patients [11-13]. However, the occurrence of plate-screw construct breakage is hard to avoid. The rate of nonunion for mid-shaft clavicle fractures is $1.4 \%$ [14], whereas that of femoral fractures is $6 \%$ to $17 \%$ [15-18]. In recent years, there has been an increase in the frequency of implant breakage along with the increasing use of plate fixation; yet, there are few studies describing the factors that contribute to this complication. The present study used a long-term follow-up of a large patient population to identify the independent risk factors associated with plate fixation breakage among patients with traumatic fractures.

Our single-factor analysis showed that the risk of fracture was associated with the weight or not weight limbs, the type of broken plate, breakage site within/outside the fracture line, the number of plate holes, the number of plate screws, and inserting screws closely adjacent to the fracture line. A multivariate Cox regression analysis

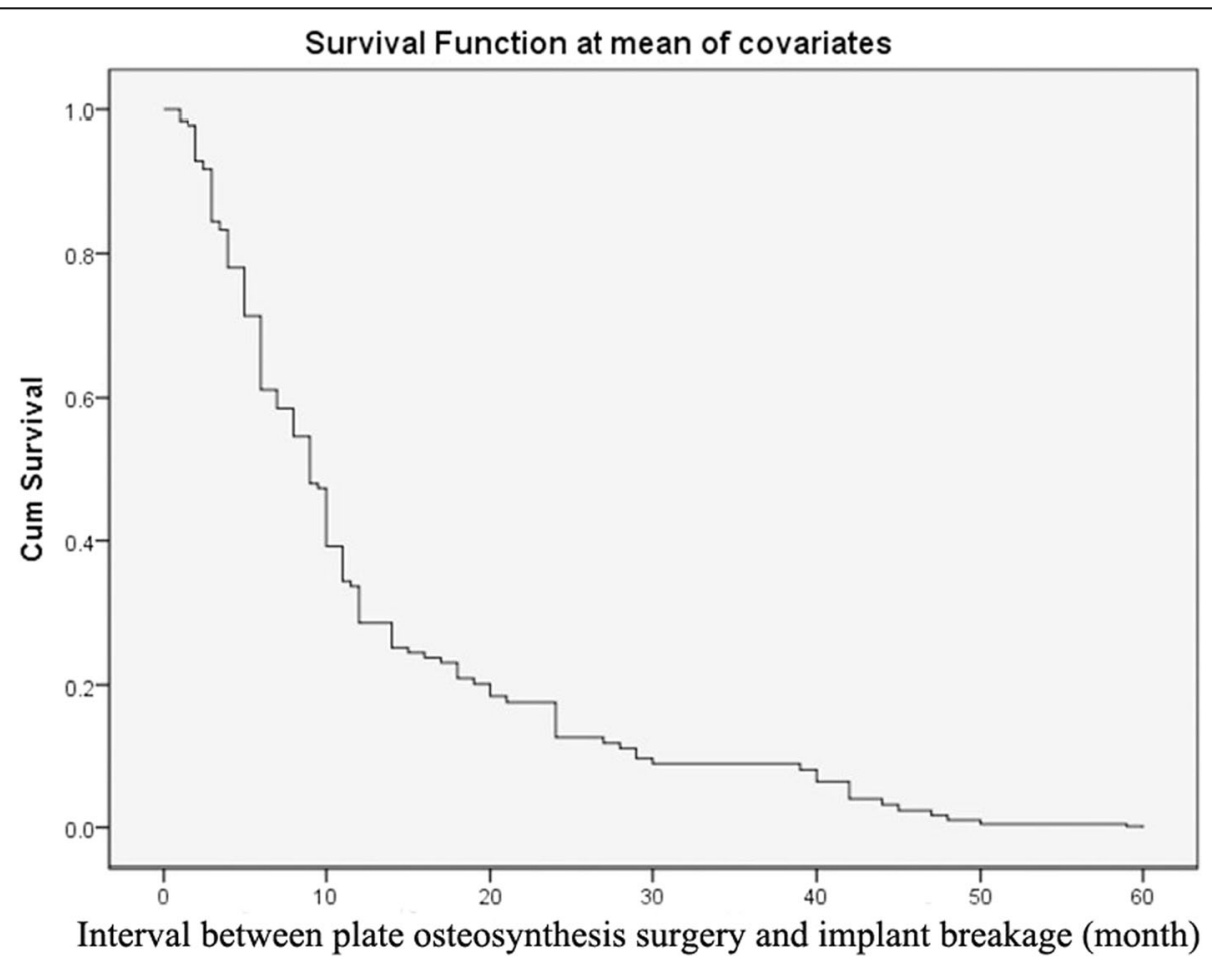

Fig. 4 Cox survival function curves for each of the covariates 
confirmed that inserting screws adjacent to the fracture line was related to an increased risk of implant breakage for patients who had a fracture of the limbs, clavicle, hands, or feet. Previous studies have reported various risk factors for implant breakage, including being female, higher comorbidity scores, surgeons with fewer years' experience, the use of longer plates, among other factors $[19,20]$; we did not identify any of these factors as risk factors in our study.

In the current study, most implant breakages occurred within the first year, just as showed in Table 1. Most patients were aged between 20 and 50 years (62.5\%), were male $(72.0 \%)$, overweight $(66.0 \%)$, and from a rural area (78.6\%). Patients at risk were more likely to have experienced a high-energy trauma $(73.8 \%)$ or complex fracture (88.1\%) to a lower limb (79.2\%), with failure occurring as a result of plate breakage (67.9\%).

Plate osteosynthesis can provide relative stability, keep the fracture in a better biological position, and promote callus formation and fracture healing [21]. For complex fractures, recommendations are to use longer plates but without placing screws into the holes adjacent to the fracture line. In addition, increasing the bridging platework length to help distribute the stress over a larger area of the plate and thereby minimize the risk of breakage is advised. Similar rules exist for the treatment of simple and comminuted fractures, with surgeons advised against placing screws into the holes adjacent to the fracture line [22, 23]. For comminuted fractures, leaving these holes empty allows for slight movement among the fracture fragments, which is beneficial for callus formation within a reasonable scope of strain [24].

Many previous studies have shown that following biological and bridge plate techniques can obtain good radiological and functional results [25-28]. In the current study, most of the surgeons (86.9\%) did not place the screws close to the fracture line; however, $13.1 \%$ of surgeons did not adhere to the principle for screw placement, and this caused an increase in the rate of plate breakage.

The presence of holes positioned adjacent to the fracture line provides an opportunity for their use, which is against recommendations. Thus, we suggest that it is unnecessary for these plates to be manufactured with these additional holes. We therefore designed a plate without holes at a part of the plate (patent number: ZL201520890025.3), and we suggest this part can be placed adjacent to the fracture line (Fig. 5). For example, surgeons can position the portion without holes in the middle for a ulnar shaft fracture, at the distal part as used in the fixation of supercondylar femoral fracture, or at the proximal part as used in the fixation of surgical neck fractrue of the humerus (Fig. 6). Another feature is that the part of the plate without holes

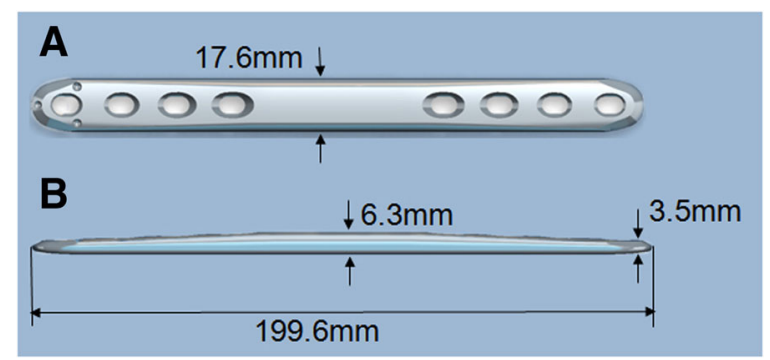

Fig. 5 The newly-designed individual plate is featured without holes in one part of the plate, which part should be placed adjacent to the fracture line. Another is that the part without holes is the thickest, becoming thinner gradually to both ends. (a, anteroposterior view; b, lateral view)

is thickest, becoming thinner gradually to both ends (Fig. 5). This kind of plate will improve the mechanical strength of the whole plate-screw construct and subsequently reduce the risk of implant breakage.

\section{Limitations}

Our study has a few limitations. First, this was a retrospective study, and inevitable recall bias exists. Second, we did not distinguish between bridge plating fixation and compression fixation because both principles were used in many of the cases and they are difficult (and somewhat unnecessary) to distinguish. Third, it is not certain precisely when the construct breakage occurred, with breakage time determined as the time of the latest radiographic evidence.

\section{Conclusions}

Using multivariate Cox regression analysis, we show that there is an increased risk of implant breakage in patients who had a fracture of the four extremities, clavicle, hand or foot after plate osteosynthesis fixation when screws were placed in the holes of the plate adjacent to the fracture line. The data also suggests that the newly-designed individual plates without holes in a part of the plate, which part should be placed adjacent to the fracture line, can help reduce the risk of implant breakage. Additional prospective studies are warranted to compare this new plate type with existing instrumentation to confirm that the placement of screws near the fracture line affect the treatment of traumatic fractures.

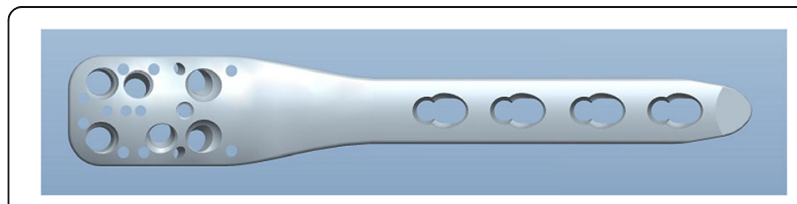

Fig. 6 The newly-designed plate used in the fixation of surgical neck fractrue of the humerus with proximal part without holes 


\section{Abbreviations}

ASA: American Society of Anesthesiologists; BMI: Body mass index; $H R_{s}$ : Calculate hazard ratios

\section{Acknowledgements}

We thank Dr. Wei Chen and Dr. Zhiyong Hou for their assistance in the analysis of the data and radiographs.

\section{Funding}

None

\section{Availability of data and materials}

All data is available at http://zhlngkykfdzzz.cthhmu.com/docs/AuthorPark/ default.aspx?pageindex $=2$. This is the websit of The Chinese Journal of Geriatric Orthopaedics and Rehabilitation, which is a department of our hospital. The website of our hospital is http://www.cthhmu.com/. The dataset used in the current study has never been reported previously in any other journal.

\section{Authors' contributions}

YZ designed the study; HL and WC searched the relevant studies and abstracted the data; PY and NY analyzed and interpreted the data; $\mathrm{HL}$ and WC wrote the draft; $H \mathrm{~L}, X Y$ and $Y Z$ revised the manuscript. $Y Z$ approved the final version of the manuscript. All authors have read and approved the final submitted manuscript.

\section{Competing interests}

The authors declare that they have no competing interests.

\section{Consent for publication}

All patients have signed the informed consents and agreed their data to be analyzed and published.

\section{Ethics approval and consent to participate}

This study was approved by the Institutional Review Board of the 3rd Hospital of Hebei Medical University. All patients agreed to participate in this study and signed the informed consents.

\section{Publisher's Note}

Springer Nature remains neutral with regard to jurisdictional claims in published maps and institutional affiliations.

Received: 14 November 2016 Accepted: 12 April 2017

\section{Published online: 21 April 2017}

\section{References}

1. Adam P, Bonnomet F, Ehlinger M. Advantage and limitations of a minimallyinvasive approach and early weight bearing in the treatment of tibial shaft fractures with locking plates. Orthop Traumatol Sur. 2012;98(98):564-9.

2. Thapa S, Thapa SK, Dhakal S, Marasini R, Hamal B, Rai RK, et al. A comparative study of fracture shaft of femur in adults treated with broad dynamic compression plate versus intramedullary interlocking nail. JCMS-Nepal. 2016;12(2):66-9.

3. Ding $L, H e ~ Z$, Xiao $H$, Chai $L$, Xue F. Factors affecting the incidence of aseptic nonunion after surgical fixation of humeral diaphyseal fracture. J Orthop Sci. 2014;19(6):973-7.

4. Belmont Jr PJ, Davey S, Rensing N, et al. Patient-based and surgical risk factors for 30-day postoperative complications and mortality after ankle fracture fixation. J Orthop Trauma. 2015:29(12):e476-e82.

5. Soong M, Leerdam RV, Guitton TG, Got C, Katarincic J, Ring D. Fracture of the distal radius: risk factors for complications after locked volar plate fixation. J Hand Surg [Am]. 2011;36(1):3-9.

6. Gardner MJ, Evans JM, Dunbar RP. Failure of fracture plate fixation. J Am Acad Orthop Surg. 2009;17(10):647-57.

7. Gautier E, Ch S. Biological internal fixation - guidelines for the rehabilitation. Ther Umsch. 2003:60(12):729-35.

8. Gautier E, Sommer C. Guidelines for the clinical application of the LCP. Injury. 2003;34 Suppl 2:B63-76.

9. Stoffel K, Dieter U, Stachowiak G, Gächter A, Kuster MS. Biomechanical testing of the LCP_how can stability in locked internal fixators be controlled? Injury. 2003;34 Suppl 2:B11-B9.
10. Sanders R, Haidukewych GJ, Milne T, Dennis J, Latta LL. Minimal versus maximal plate fixation techniques of the ulna: the biomechanical effect of number of screws and plate length. J Orthop Trauma. 2002;16(3):166-71.

11. Pennington SD, Duralde XA. Locking plate fixation for proximal humerus fractures. Am J Orthop. 2014;43(7):302-8.

12. Solberg BD, Moon CN, Franco DP, Paiement GD. Surgical treatment of three and four-part proximal humeral fractures. Orthop Traumatol Sur. 2009;91(7):1689-97.

13. Ruchholtz S, Hauk C, Lewan U, Franz D, Kühne C, Zettl R. Minimally invasive polyaxial locking plate fixation of proximal humeral fractures: a prospective study. J Trauma. 2011;71(6):1737-44.

14. Mckee RC, Whelan DB, Schemitsch EH, Mckee MD. Operative versus nonoperative care of displaced midshaft clavicular fractures: a metaanalysis of randomized clinical trials. JBJS. 2012;94(8):675-84.

15. Ricci WM, Loftus T, Cox C, Borrelli J. Locked plates combined with minimally invasive insertion technique for the treatment of periprosthetic supracondylar femur fractures above a total knee arthroplasty. J Orthop Trauma. 2006;20(3):190-6.

16. Kregor PJ, Stannard JA, Zlowodzki M, Cole PA. Treatment of distal femur fractures using the less invasive stabilization system: surgical experience and early clinical results in 103 fractures. J Orthop Trauma. 2004;18(8):509-20.

17. Haidukewych G, Sems SA, Huebner D, Horwitz D, Levy B. Results of polyaxial locked-plate fixation of periarticular fractures of the knee. J Bone Joint Surg Am. 2007:89(3):614-20.

18. Ricci WM Jr BJ. Operative management of periprosthetic femur fractures in the elderly using biological fracture reduction and fixation techniques. Injury. 2007;38 Suppl 3:S53-8.

19. Leroux T, Wasserstein D, Henry P, Khoshbin A, Dwyer T, Ogilvie-Harris D, et al. Rate of and risk factors for reoperations after open reduction and internal fixation of midshaft clavicle fractures: a population-based study in Ontario. Canada J Bone Joint Surg Am. 2014;96(13):1119-25.

20. Ricci WM, Streubel PN, Morshed S, Collinge CA, Nork SE, Gardner MJ. Risk factors for failure of locked plate fixation of distal femur fractures: an analysis of 335 cases. J Orthop Trauma. 2014;28(2):83-9.

21. Perren SM. Evolution of the internal fixation of long bone fractures. The scientific basis of biological internal fixation: choosing a new balance between stability and biology. J Bone Joint Surg (Br). 2002:84(84):1093-110.

22. Schmidtmann U, Knopp W, Wolff C, Stürmer KM. Results of elastic plate osteosynthesis of simple femoral shaft fractures in polytraumatized patients. An alternative procedure. Unfallchirurg. 1997;100(12):949-56.

23. Stürmer KM. Elastic plate osteosynthesis, biomechanics, indications and technique in comparison with rigid osteosynthesis. Unfallchirurg. 1996;99(11):816-29.

24. Perren SM. The concept of biological plating using the limited contactdynamic compression plate (LC-DCP). Scientific background, design and application. Injury. 1991;22 Suppl 1:1-41.

25. Baumgaertel F, Gotzen L. The "biological" plate osteosynthesis in multifragment fractures of the para-articular femur. A prospective study. Unfallchirurg. 1994;97(2):78-84.

26. Krettek C, Schandelmaier P, Miclau T, Bertram R, Holmes W, Tscherne H. Transarticular joint reconstruction and indirect plate osteosynthesis for complex distal supracondylar femoral fractures. Injury. 1997;28(1):A31-41.

27. Wenda K, Runkel M, Degreif J, Rudig L. Minimally invasive plate fixation in femoral shaft fractures. Injury. 1997;28 Suppl 1:A13-9.

28. Cole PA, Zlowodzki M, Kregor PJ. Treatment of proximal tibia fractures using the less invasive stabilization system: surgical experience and early clinical results in 77 fractures. J Orthop Trauma. 2004;18(8):528-35. 